\title{
A TRANSFORMAÇÃO DO TRABALHADOR RURAL EM APOSENTADO *
}

Benedita E. S. Lima Cabral **

\section{A PREVIDENNCIA SOCIAL E A APOSENTADORIA DO TRABALHADOR RURAL}

O processo de concretização dos direitos previdenciários obtidos através do FUNRURAL revela a fragilidade da polftica social. Existem dois sistemas previdenciários distintos: um para a população urbana e outro para a população rural, cada um deles dispondo de uma forma própria de custeio e de uma pauta de benefícios e serviços, que, embora guardando entre si alguma semelhanç, diferem qualitativa e quantitativamente.

O custeio (1) da Previdéncia urbana está baseado em contribuições fixas descontadas sobre o salário do trabalhador e contribuições das empresas de um valor proporcional à folha de salários de seus empregados, recolhidos mensalmente. A legislação determina que compete ao Governo Federal participação nas despesas com pessoal e complementação de verbas quando há déficit orçamentário. O custeio do PRORURAL (2) não está relacionado diretamente com pagamentos salariais de trabalhadores rurais.

Na ausência de uma contribuição individualizada para o PRORURAL, como ocorre no sistema previdenciário urbano, não foi dif /cil difundir-se no meio rural a crença de que os beneff́cios desse programa são gratuitos, são dádivas. Esta idéia, entretanto, não resiste à análise dos procedimentos adotados pelo Estado para cobrar indiretamente a contribuição. As formas de pagamento vigentes na agricultura e os baixos salarios pagos no meio Rural, inferiores ao salário-minimo oficial, ou o preço ménimo pago pela produção agrícola, quando se trata de pequenos produtores, trazem também embutidos descontos para a previdéncia, que posteriormente são recolhidos como contribulção. Como esta informação não é transmitida ao TR "**' 'nem à maioria dos pequenos produtores, os mecanismos institucionais de cobrança de taxas previdenciárias são por eles desconhecidos, e eles permanecem ignorando sua própria participação neste fundo de custeio.

O TR conhece outras taxas, como a contribuiçăo sindical obrigatória (3), que é o desconto de um dia de salário por ano, subtra f́do de seu pagamento no mês de março como o "Dia do Governo", expressão amplamente utilizada na Zona da Mata de Pernambuco, por exemplo, (cf. Sigaud, 1979), e, também, a mensalidade sindical, que não obrigatória, mas, freqüentemente confundida como pagamento para "ter direitos" (4). Os trabalhadores rurais também identificam 0 ato de associar-se ao sindicato e pagar mensalidades como uma filiação ao sistema Previdenciário, face à forma como o FUNRURAL aparece, diretamente vinculado ao Sindicato. Os depoimentos da maioria dos TRs demonstram essa compreensão, favorecida pela forma como o FUNRURAL se instalou via convênios com os sindicatos, contribuindo diretamente para que a prática sindical se aliasse com a ação institucional do programa previdenciá. rio para o campo.

(*) Originalmente, capítulo da dissertação de mestrado "De Trabalhadores a Aposentados do PRORURAL. As contradições da Politica Social e a Concessăo tardia de Direitos." Em 30.12.86.

(*) Professora do Departamento de Sociologia e Antropologia, UFPb, Campus II

(***) Trabalhador Rural 
A ausência de informações corretas e o desconhecimento do processo histórico que antecede a conquista dos direitos parecem contribuir para acentuar a conotação beneplácita predominante entre os trabalhadores rurais beneficiários da previdencia que comumente relacionam o acesso aos direitos à conduta moral. Multos julgam que, para se fazerem merecedores das concessões do PRORURAL, devem observar multa retidão de comportamento e caráter.

\section{A CONDIÇÃO DE APOSENTADO: UM CARNE E AS NOVAS EXPECTATIVAS}

No momento em que o TR recebe o carnê de aposentadoria, inicia-se uma nova fase em sua vida. O carné é a concretização do direito. Através dele os trabalhadores, agora aposentados, terão acesso ao benefício. Pela primeira vez, muitos se dirigem a uma instituição bancária onde receberão mensalmente o auxflio pecuniário. As alterações da nova situação introduzem-se no cotidiano do aposentado, e são considerados como "mudanças para melhor" por todos os entrevistados. Ao narrarem as próprias experiências, eles indicam como se produzem essas modificações, reconhecendo a aposentadoria como uma "renda certa" e de procedência "gratuita" que, embora pequena, por não atender a suas necessidades, permite garantir uma cota de alimentos. Simultaneamente, verifica-se que os aposentados permanecem em atividade produtiva, apesar da idade $e$ da obtenção do dire ito.

O novo recurso, entretanto, modifica para menos o "quantum" de trabalho dispendido pelo TR para atingir as despesas necessárias à sua manutenção. Segundo as histórias de vida dos aposenados, é possivel, a partir da aposentadoria, realizar suas tarefas de forma menos rígida, podendo inclusive retirar-se do "alugado" e dedicar-se a uma so atividade na terra aforada ou de pequena propriedade, que cultivam em comum com parentes de todas as idades.

Os aposentados que permanecem trabalhando revelam dois fatores determinantes para suapermanência em atividade produtiva - dispor de alguma parcela de terra para cultivo e contar com um nivel de saúde razoável.

A aposentadoria aparece como um alivio à carga de trabalho, ao mesmo tempo em que se configura como uma forma de autonomia, face à dependência econômica de filhos ou parentes. Na opinião de alguns aposentados a conquista da aposentadoria significou a superaçáo desses obstáculos.

Por outro lado, a "renda certa" da aposentadoria é condição objetiva de poder aquisitivo, com efeitos sobre o nivel de consumo da população atingida. Imagine-se, por exemplo, uma localidade, distante de centros urbanos, com pouca circulação monetária e limitada estrutura do emprego, o efeito provocado pelo recebimento simultâneo de benefícios por muitos de seus residentes aposentados e o resultado imediato gerado a partir desse rendimento.

No conjunto das mudanças, a posse dos documentos civis e o carné de aposentadoria de que agora dispõem apresentam-se como garantias para sua inserção no mercado de consumo. Munidos desses instrumentos, eles obtêm crédito para comprar alimentos em mercearias locais. Isto 6 facilitado pelo conhecimento de que o aposentado tern um carnê que lhe garante uma "renda certa" mensalmente.

Esse aspecto positivo da situação atual foi relacionado por alguns, em contraposição à situação passada, quando era difícil obter gêneros no "fiado", e havia a incerteza do pagamento. Para os que vivem exclusivamente da aposentadoria, este aspecto é fundamental, conforme expressou um aposentado. 
"Mudou muito depois da aposentadoria, melhorou demais. A mercearia vende "fiado", pois sabe que vou pagar quando receber no fím do mês."

(A.D.S., 66 anos, residente urbano).

O tamanho dessa renda determina a dimensão do crédito, que fica contido numa importåncia máxima equivalente ao valor do benefício.

O carnê também promove o intercámbio entre O TR, O FUNRURAL e a rede bancária, considerado aspecto importante introduzido pela nova situação. $O$ aposentado comparece mensalmente ao banco para retirar o dinheiro do beneffcio e apresenta-se ao FUNRURAL a cada semestre para atualizar o valor do carnê e comprovar sua própria existência.

\section{CONCLUSÃO}

Os trabalhadores do campo que se iniciam precocemente na atividade produtiva devem esperar até 65 anos de idade para obter a Aposentadoria por Velhice. A expectativa de vida dessa população, em torno de 50 anos de idade, retira, pela mortalidade, parcela expressiva que não sobreviverá o tempo necessário para usufruir deste direito. Adicionalmente, o ritual a que se submete para receber a Aposentadoria inverte de certa forma o processo: ele deve apresentar documentos que o deveriam tornar apto a ingressar no mundo do trabalho, quando teoricamente dele se retira.

0 processo de habilitação ao benefício, impõe ao trabalhador submissâo às exigências documentais $\theta$, dentre elas, a declaração de sua condição de trabalhador rural. Aquilo que não conseguira lograr durante a vida, como o registro de suas relações de trabalho, deve fazer agora. No passado, para colocar-se à disposição do processo produtivo agricola, não foi necessário formalidade alguma, entretanto, para retirar-se das atividades, deve atender às normas institucionais, colocando-se à mercê de declarações de proprietários rurais, os quais, em sua maioria, sempre negaram aos trabalhadores o direito de seus vínculos de trabalho.

Esse movimento contraditório não é percebido pelos aposentados, que se valem de conhecimentos pessoais e dos dirigentes sindicals para obter as declarações necessárias, quando requerem a aposentadoria. As mediações politicas fazem-se presentes. A concessão de quaisquer declarações estabelece um vinculo de gratidão do trabalhador para com aquele que o atende.

A interferência do poder político local nos procedimentos do FUNRURAL aparece com regularidade, o que torna o processo de escolha do Representante Local da Entidade uma acirrada disputa politico-partidária.

A formalidade que reveste os procedimentos necessários ao exercicio tardio da cidadania pelos trabalhadores. rurais, expressa-se na obtenção da carteira de trabalho aos 65 anos de idade. $O$ brilho azul das carteir as recém-obtidas poderia simbolizar a inan dequacaão dos procedimentos burocráticos a uma realidade a que se amolda artificialmente, face à necessidade do trabalhador obter um beneficio, mesmo que tardiamente. A carteira é necessária, apesar de que, ali, jamais venha a ser registrado qualquer contrato de trabalho.

Receber o carnê de aposentadoria é o marco de uma nova etapa na trajetória dos trabalhadores. A esse carnê deve ser relacionado ao nivel de pauperização que atinge progressivamente os trabalhadores, quando uma renda de meio salário mínimo pode suprir suas próprias necessidades. 
Tendo vivido à margem dos direitos, os aposentados não conseguem discernir, no pequeno benefício auferido, um retorno da sociedade, na tentativa de resgatar sua divida social para com eles. Por desconhecerem a articulação entre as forças sociais que os exploram, os aposentados parecem sensiveis ao "mito da outorga", considerando a aposentadoria como "benesse", com graça.

O grupo estudado também demonstrou a forte presença da lógica de que se deve "pagar para ter direitos". Por näo terem esse tipo de prática como contribuintes diretos (com raras exceções), não conseguem perceber o "quantum" de sua participação para o enriquecimento da sociedade, não associam sua contribuicão geral com os benefícios hoje recebidos.

A "renda certa" da aposentadoria não é, contudo, suficiente para retirar a maioria da atividade produtiva. Eles permanecem trabalhando e, neste caso, 0 benefficio é um complemento a suas despesas, enquanto a renda principal continua provindo de seu trabalho. Os que têm acesso à terra, sobrepõem-se às doenças e à idade avançada, para continuarem produzindo além dos 70 anos. Algumas expectativas otimistas aparecem no discurso dos que pretendem dar um novo rumo a suas vidas a partir da condição de aposentado.

A transformação do trabalhador em aposentado revelou as ambiguidades da poIltica social, onde o Estado aparece coerente com o movimento das relações de trabaTho rurais ao adotar o modelo assistencial. A legislação do PRORURAL homogeneiza as várias condições de trabalho na categoria Trabalhador Rural, unificando, de forma superficial, a complexa realidade e sobrepondo-se aos interesses dos trabalhadores.

$\mathrm{Na}$ implementação do programa e para intermediar o processo, o Estado apoia-se na estrutura sindical, comprometendo suas atribulçőes de representação de classe. o caráter assistencial da atividade sindical sobrepõe-se, gerando confusão entre os TRs por não distinguirem o especffico do PRORURAL na prática sindical. Essa intermediação também contribui para eludir os limites do programa, concentrando-se nos sindicatos o conjunto de atividades oferecidas, o que obriga os trabalhadores a buscarem ali solução para alguns problemas como, doença, velhice e morte.

Entretanto, são as precárias condições de existência desses TRs que vão reforçar as ações do Estado na área rural, porque elas se apresentam como oportunidade única o real de retribuir o esforço por eles despendido para o conjunto da sociedade. Há, portanto, uma atitude de gratidão do aposentado ao Estado, pelo reconhecimento de seu "status" de cidadão, quando se esperaria o protesto por ter permanecido à margem de seus direitos durante o ciclo de sua vida produtiva. 
(1) Ver Art. 33 do Dec. 83.081/79 sobre Contribuições para o Custeio da Previdência Social Urbana. Ver tambem o Dec. Lei 1.910/81 que modificou os indices dessas contribuições de um valor padrão de $8 \%$ para Indices variáveis entre 8,5 e $10 \%$ sobre os salários, conforme a faixa salarial. As empresas tiveram suas contribuições padronizadas para $10 \%$ sobre a folha de salários dos empregados. O Estado permaneceu conforme legislação anterior.

(2) o Art. 76 do Dec. 83.081/79 determina o Custeio da Previdência Rural nas seguintes bases: uma taxa mensal equivalente a $2,5 \%$ do valor comercial dos produtos rurais pago pelo produtor; e outra taxa de $2,4 \%$ sobre a folha de salários das empresas vinculạdas à Previdência Urbana e recolhidas mensalmente junto ans demais tributos previdenciários.

(3) Arts. 578 e 610 da CLT (Dec. Lei n? 55.452, de 01/05/43) tratam da Contribuição Sindical obrigatória, bem como da forma de sua arrecadação, administração pelo Ministério do Trabatho, aplicação e penalidades. As análises de Gomes e Gottschalk (1984) pp. $710-715$ e os "comentários" de Russomano (1983) pp. 677-691, oferecem elementos esclarecedores para compreensão da Contribuição Sindical obrigatória que incide nas relações de trabalho no Brasil, além de destacar a questão do sindicato atrelado ao Estado, "ponto fulcral a ser considerado: embora sendo pessoa jurídica de Direito Privado, o Sindicato aufere rendas impostas por le $i$, isto é, criadas pelo Estado". (Russomano, op. cut. p. 657).

(4) Ver Sigaud (1979) p. 224. A autora aborda a questão do ponto de vista da representaçâa do TR, de que "é preciso que se pague pelos direitos". 